University of South Carolina

Scholar Commons

2008

\title{
Where's the Kale? Environmental Availability of Fruits and Vegetables in Two Racially Dissimilar Communities
}

\author{
Edith M. Williams \\ University of South Carolina - Columbia, willi425@mailbox.sc.edu \\ Bamidele 0. Tayo \\ Beverly McLean \\ Ellen Smit \\ Christopher T. Sempos
}

See next page for additional authors

Follow this and additional works at: https://scholarcommons.sc.edu/

sph_epidemiology_biostatistics_facpub

Part of the Public Health Commons

\section{Publication Info \\ Published in Environmental Justice, ed. Sylvia Hood Washington, Volume 1, Issue 1, 2008, pages 35-43. \\ This is a copy of an article published in Environmental Justice (c) 2008 (c) Mary Ann Liebert, Inc.; \\ Environmental Justice is available online at: http://online.liebertpub.com. \\ Williams, E.M., Tayo, B.O., McLean, B., Smit, E., Sempos, C.T., \& Crespo, C.J. (2008). Where's the Kale? Environmental Availability of Fruits and Vegetables in Two Racially Dissimilar Communities. \\ Environmental Justice, 1(1), 35-43. DOI: 10.1089/env.2008.0503 \\ (C) 2008 Mary Ann Liebert, Inc.}

This Article is brought to you by the Epidemiology and Biostatistics at Scholar Commons. It has been accepted for inclusion in Faculty Publications by an authorized administrator of Scholar Commons. For more information, please contact digres@mailbox.sc.edu. 


\section{Author(s)}

Edith M. Williams, Bamidele O. Tayo, Beverly McLean, Ellen Smit, Christopher T. Sempos, and Carlos J. Crespo 


\title{
Where's the Kale? Environmental Availability of Fruits and Vegetables in Two Racially Dissimilar Communities
}

\author{
Edith M. Williams, Bamidele O. Tayo, Beverly McLean, Ellen Smit, \\ Christopher T. Sempos, and Carlos J. Crespo
}

\begin{abstract}
Minority communities across the United States have limited numbers of stores that offer a variety of fruits and vegetables, creating major barriers to good eating habits and nutritional practices among minority groups such as African Americans. Factors like environmental availability of healthy food options have not been fully investigated as possible sources of current cross-population differences in disease. The present study examined whether a predominantly African American neighborhood had disproportionately less availability of fruits and vegetables than a predominantly non-Hispanic White neighborhood. Availability was judged on the bases of the types of stores available in each community and the specific types of fruits and vegetables made available in each store. The availability of fruits and vegetables in the food stores of each community was assessed by physically canvassing neighborhood food stores and taking a census of available fruit and vegetable items based on a list of fruits and vegetables derived from the DASH diet. The predominantly African American community under study had fewer varieties of fresh fruits and vegetables and fewer stores offering larger varieties of fruits and vegetables. Reduced choice to purchase fruits and vegetables among minority populations potentially increases health disparities. Improving local food environments is one important strategy to increase access to a healthy diet in minority communities.
\end{abstract}

\section{INTRODUCTION}

$\mathbf{M}$ INORITY COMMUNITIES ACROSS the United States have poorly developed food distribution systems. Limited numbers of stores and other food outlets that offer a variety of healthy food options have created major barriers to good eating habits and nutritional practices among residents of poor and nonwhite communities. There has been growing recognition of the connection between disparities in nutritional status across racial/ethnic lines and options minority communities have for grocery purchases. ${ }^{1}$

Dr. WIlliams is Research Assistant Professor at the Institute for Partnerships to Eliminate Health Disparities at the University of South Carolina in Columbia, SC; Dr. Tayo is Research Assistant Professor at Loyola University in Maywood, IL; Dr. McLean is Research Assistant Professor at University at Buffalo, State University of New York, School of Architecture and Planning; Dr. Smit is Research Associate Professor at Portland State University; Dr. Sempos is Scientific Review Administrator at the National Institutes of Health Office of Research on Minority Health in Bethesda, MD; and Dr. Crespo is Director, School of Community Health at Portland State University.
A healthy and nutritional diet is a key component in addressing the health problems of minorities, particularly for African Americans. Several studies have shown that adverse dietary patterns are related to a worsened health profile among African Americans, compared to Whites, for diseases such as obesity, hypertension, diabetes, coronary heart disease (CHD), and certain types of cancer. A substantial body of clinical and epidemiological evidence shows many common links between diet and disease. Several studies have shown that a diet rich in vegetables and fruit protects against cardiovascular

${ }^{1}$ Baker, E, C Kelly, E Barnidge, J Strayhorn, M Schootman, J Struthers, and D Griffith. "The Garden of Eden: Acknowledging the Impact of Race and Class in Efforts to Decrease Obesity Rates." American Journal of Public Health 96 (2006): 1170-74; Cheadle, A, BM Psaty, S Curry, E Wagner, P Diehr, T Koepsell, and A Kristal. "Community-Level Comparisons between the Grocery Store Environment and Individual Dietary Practices." Preventive Medicine 20 (1991): 250-61; Eisenhauer, E. "In Poor Health: Supermarket Redlining and Urban Nutrition." GeoJournal 53 (2001): 125-33; Morland, K, S Wing, and A Diez-Roux. "The Contextual Effect of the Local Food Environment on Residents' Diets: 
disease, obesity, and diabetes. The results of the Dietary Approaches to Stop Hypertension (DASH) trials suggest that a diet rich in fruits and vegetables can substantially lower blood pressure and provide an additional nutritional approach to the prevention and treatment of hypertension. This was particularly true among African Americans. ${ }^{2}$

Although such studies suggest that a lack of access to healthy food is another type of health disparity, few studies have investigated the location, characteristics (e.g., type of store, what sold, prices) and number of food stores in minority communities, and the availability of food stores in the immediate local environment offering a variety of fruits and vegetables has not been extensively investigated as an environmental factor possibly contributing to current cross-population differences in disease. Therefore the purpose of this study was to determine whether a predominantly African American neighborhood had less availability of fruits and vegetables than a predominantly White neighborhood based on what was offered in each community's corresponding food outlets. ${ }^{3}$

\section{METHODS}

The current study was approved by the Health Sciences Institutional Review Board (IRB) at the State University of New York at Buffalo. Consent was not required since human subjects were not involved. However, store owners were informed of the purpose of store surveillance. The present study was designed to evaluate whether food stores in a predominantly African American community offered fewer varieties of fruit and vegetables than food stores in an adjacent predominantly White community. The data collected describe the food stores at one point in time, showing a cross-sectional availability of fruit and vegetable items in the stores.

\section{Study population}

The aim of this study was to compare the availability of fruits and vegetables across racial/ethnic lines. Two communities were selected that were geographically similar so as to rule out geographical variation as a potential predictor of store location and characteristics. Both com-
The Atherosclerosis Risk in Communities Study." American Journal of Public Health 92 (2002): 1761-67; UB Center for Urban Studies School of Architecture and Planning, UB Center for Research in Primary Care, and The Black Leadership Forum. "The Health Status of the near East Side Black Community: Wellness and Neighborhood Conditions." Buffalo, NY, 2001; Glanz, K, M Basil, E Maibach, J Goldberg, and D Snyder. "Why Americans Eat What They Do: Taste, Nutrition, Cost, Convenience, and Weight Control Concerns as Influences on Food Consumption." Journal of the American Dietetic Association 98 (1998): 1118-26; Kaufman, PR, JM MacDonald, SM Lutz, and DM Smallwood. "Do the Poor Pay More for Food? Item Selection and Price Differences Affect Low-Income Household Food Costs." Washington, DC: United States Department of Agriculture, Economic Research Service, 1997; Turrell, G. "Structural, Material, and Economic Influences of the Food Purchasing Choices of Socioeconomic Groups." Australia New Zealand Journal of Public Health 20 (1996): 11-17; US House of Representatives Select Committee on Hunger. "Obtaining Food: Shopping Constraints of the Poor, Committee Report." Washington, DC: US Government Printing Office, 1987; US House of Representatives Select Committee on Hunger. "Urban Grocery Gap, Committee Report." Washington, DC: US Government Printing Office, 1992; Wechsler, H, CE Basch, P Zybert, R Lantigua, and S Shea. "The Availability of Low-Fat Milk in an Inner-City Latino Community: Implications for Nutrition Education." American Journal of Public Health 85 (1995): 1690-92; Zenk, S, A Schultz, B Israel, J Sherman, S Bao, and M Wilson. "Neighborhood Racial Composition, Neighborhood Poverty, and the Spatial Accessibility of Supermarkets in Metropolitan Detroit." American Journal of Public Health 95 (2005): 660-67; Morrill, AC and CD Chinn. "The Obesity Epidemic in the United States." Journal of Public Health Policy 25, no. 3-4 (2004): 353-66; Jetter, KM and DL Cassady. "The Availability and Cost of Healthier Food Alternatives." American Journal of Preventive Medicine 30, no. 1 (2006): 38-44; Morland, K, S Wing, A Diez-Roux, and C Poole. "Neighborhood Characteristics Associated with the Location of Food Stores and Food Service Places." American Journal of Preventive Medicine 22 (2002): 23-29; Yen, IH and GA Kaplan. "Neighborhood Social Environment and Risk of Death: Multilevel Evidence from the Alameda County Study." American Journal of Epidemiology 149 (1999): 898-907; Morland, K, AV
Diez-Roux, and S Wing. "Supermarkets, Other Food Stores, and Obesity: The Atherosclerosis Risk in Communities Study." American Journal of Preventive Medicine 30, no. 4 (2006): 333-39.

${ }^{2}$ Deckelbaum, RJ, EA Fisher, M Winston, S Kumanyika, RM Lauer, FX Pi-Sunyer, S St. Jeor, EJ Schaefer, and IB Weinstein. "Summary of a Scientific Conference on Preventive Nutrition: Pediatrics to Geriatrics." Circulation 100 (1999): 450-56; Houston, DK, J Stevens, J Cai, and PS Haines. "Dairy, Fruit, and Vegetable Intakes and Functional Limitations and Disability in a Biracial Cohort: The Atherosclerosis Risk in Communities Study." American Journal of Clinical Nutrition 81 (2005): 515-22; Solomons, NW. "Diet and Long-Term Health: An African Diaspora Perspective." Asia Pacific Journal of Clinical Nutrition 12 (2003): 313-30; Dagenais, GR, R Marchioli, S Yusuf, and G Tognoni. "Beta-Carotene, Vitamin C, and Vitamin E and Cardiovascular Diseases." Current Cardiology Reports 2 (2000): 293-99; Gaziano, JM, JE Manson, LG Branch, GA Colditz, WC Willett, and JE Buring. "A Prospective Study of Consumption of Carotenoids in Fruits and Vegetables and Decreased Cardiovascular Mortality in the Elderly." Annals of Epidemiology 5 (1995): 255-60; Joshipura, KJ, FB Hu, JE Manson, MJ Stampfer, EB Rimm, FE Speizer, G Colditz, A Ascherio, B Rosner, D Spegelman, and WC Willett. "The Effect of Fruit and Vegetable Intake on Risk for Coronary Heart Disease." Annals of Internal Medicine 134 (2001): 1106-14; Suter, P. "The Effects of Potassium, Magnesium, Calcium, and Fiber on Risk of Stroke." Nutrition Reviews 57 (1999): 84-88; Tucker, K. "Dietary Patterns and Blood Pressure in African Americans." Nutrition Reviews 57 (1999): 356-58.

${ }^{3}$ Cheadle, A, BM Psaty, S Curry, E Wagner, P Diehr, T Koepsell, and A Kristal. "Community-Level Comparisons between the Grocery Store Environment and Individual Dietary Practices.": 250-61; Morland, K, S Wing, and A Diez-Roux. "The Contextual Effect of the Local Food Environment on Residents' Diets: The Atherosclerosis Risk in Communities Study.": 1761-67; Morland, K, S Wing, A Diez-Roux, and C Poole. "Neighborhood Characteristics Associated with the Location of Food Stores and Food Service Places.": 23-29; Yen, IH and GA Kaplan. "Neighborhood Social Environment and Risk of Death: Multilevel Evidence from the Alameda County Study.": 898-907; Morland, K, AV Diez-Roux, and S Wing. "Supermarkets, Other Food Stores, and Obesity: The Atherosclerosis Risk in Communities Study.": 333-39. 
munities were located in Erie County, New York, directly adjacent to each other. The two communities were geographically characterized by zip codes 14226 and 14215 . Descriptions of the communities were based on the following characteristics: racial/ethnic minority concentration, sex, age, educational attainment, employment status, income, poverty, housing environment, and household characteristics (ownership, rentals, size of household, tenure, vacancy). Demographic and housing characteristics for each community were obtained from the US Census Bureau (2000). ${ }^{4}$

\section{Food stores}

Since the primary aim of the study was to investigate the availability of fruits and vegetables in two communities, stores were included that sold fruits and vegetables, and were limited to the places where neighborhood residents were most likely to purchase groceries and other household needs on a regular basis. Previous studies have found that both supermarkets and smaller neighborhood stores serve as major food shopping outlets for households. Therefore food stores considered grocery stores, supermarkets, and convenience stores were classified according to the North American Industrial Classification System (NAICS) definitions. ${ }^{5}$

Within the food and beverage category, however, supermarkets are not distinguished from other grocery stores. For this reason, NAICS codes 44510 and 44511 and their corresponding definitions were modified to describe the various types of food stores located in each target community. Supermarkets were defined as large, corporate-owned chain stores and grocery stores were defined as smaller, non-corporate owned food stores. Corner stores were defined as even smaller, mom and pop type food stores, usually located on corners of residential streets, which is consistent with previous studies of the local food environment. We created an "other" category for those stores that did not exactly match the NAICS or modified definitions. For example, the Buffalo, NY area boasts a chain of convenience stores that offer a line of food products that one would expect from a grocery store, based on NAICS criteria. This particular string of convenience stores is owned and operated by a major supermarket chain that makes some of their products available in these smaller food stores. To avoid the subjectivity involved in attempting to place such stores in one category when they meet the criteria of more than one classification, a separate category was created. A list of stores was generated using the phone book and physical inspection of each target community. Ultimately, 51 food stores were identified for the study: 10 in Community A (zip code 14226) and 41 in Community B (zip code 14215). ${ }^{6}$

\section{Assessment tool}

The DASH trials list of foods was used to create a tool that would enable us to assess whether the food stores carried the fruit and vegetable items provided as part of a dietary intervention to lower blood pressure in a population at risk for hypertension. The assessment tool (Fig. 1) included 15 fruit types and 16 vegetable types, which were further categorized into fresh, canned, and frozen varieties. Therefore, there were a total of 93 possible fruit and vegetables types. Since the variety of fruits and vegetables, and not the variety of brand names of the same item, was the information relevant to the aims of the study, data on brand names were not collected.7

${ }^{4}$ US Bureau of the Census. "Profile of General Demographic Characteristics for Zctas 14215 and 14226." US Bureau of the Census, 2000.

${ }^{5}$ Morland, K, S Wing, and A Diez-Roux. "The Contextual Effect of the Local Food Environment on Residents' Diets: The Atherosclerosis Risk in Communities Study.": 1761-67; UB Center for Urban Studies School of Architecture and Planning, UB Center for Research in Primary Care, and The Black Leadership Forum. "The Health Status of the near East Side Black Community: Wellness and Neighborhood Conditions."; Glanz, K, M Basil, E Maibach, J Goldberg, and D Snyder. "Why Americans Eat What They Do: Taste, Nutrition, Cost, Convenience, and Weight Control Concerns as Influences on Food Consumption.": 1118-26; Kaufman, PR, JM MacDonald, SM Lutz, and DM Smallwood. "Do the Poor Pay More for Food? Item Selection and Price Differences Affect Low-Income Household Food Costs."; Turrell, G. "Structural, Material, and Economic Influences of the Food Purchasing Choices of Socioeconomic Groups.": 11-17; US House of Representatives Select Committee on Hunger. "Obtaining Food: Shopping Constraints of the Poor, Committee Report."; US House of Representatives Select Committee on Hunger. "Urban Grocery Gap, Committee Report."; US Bureau of the Census. "1997 Naics Definitions." 2000.

${ }^{6}$ Morland, K, S Wing, and A Diez-Roux. "The Contextual Effect of the Local Food Environment on Residents' Diets: The Atherosclerosis Risk in Communities Study.": 1761-67; UB Center for Urban Studies School of Architecture and Planning, UB Center for Research in Primary Care, and The Black Leadership Forum. "The Health Status of the near East Side Black Community: Wellness and Neighborhood Conditions."

${ }^{7}$ Appel, LJ, WM Vollmer, E Obarzanek, KM Aicher, PR Conlin, BM Kennedy, JB Charleston, PM Reams, and DASH Collaborative Research Group. "Recruitment and Baseline Characteristics of Participants in the Dietary Approaches to Stop Hypertension Trial." Journal of the American Dietetic Association 99 (1999): S69-S75; Conlin, PR, D Chow, ER Miller, LP Svetkey, P-H Lin, DW Harsha, TJ Moore, FM Sacks, LJ Appel, and DASH Research Group. "The Effect of Dietary Patterns on Blood Pressure Control in Hypertensive Patients: Results from the Dietary Approaches to Stop Hypertension (Dash) Trial." American Journal of Hypertension 13 (2000): 949-55; Karanja, NM, E Obarzanek, P-H Lin, ML McCullough, KM Phillips, JF Swain, CM Champagne, KP Hoben, and DASH Collaborative Research Group. "Descriptive Characteristics of the Dietary Patterns Used in the Dietary Approaches to Stop Hypertension Trial." Journal of the American Dietetic Association 99 (1999): S19-S27; Obarzanek, E, FM Sacks, WM Vollmer, GA Bray, ER Miller, P-H Lin, NM Karanja, MM Most-Windhauser, TJ Moore, JF Swain, CW Bales, MA Proschan, and DASH Research Group. "Effects on Blood Lipids of a Blood Pressure-Lowering Diet: The Dietary Approaches to Stop Hypertension (Dash) Trial." American Journal of Clinical Nutrition 74 (2001): 80-89; Vogt, TM, LJ Appel, E Obarzanek, TJ Moore, WM Vollmer, LP Svetkey, FM Sacks, GA Bray, JA Cutler, MM Windhauser, PH Lin, NM Karanja, and DASH Collaborative Research Group. "Dietary Approaches to Stop Hypertension: Rationale, Design, and Methods." Journal of the American Dietetic Association 99 (1999): S12-S18. 


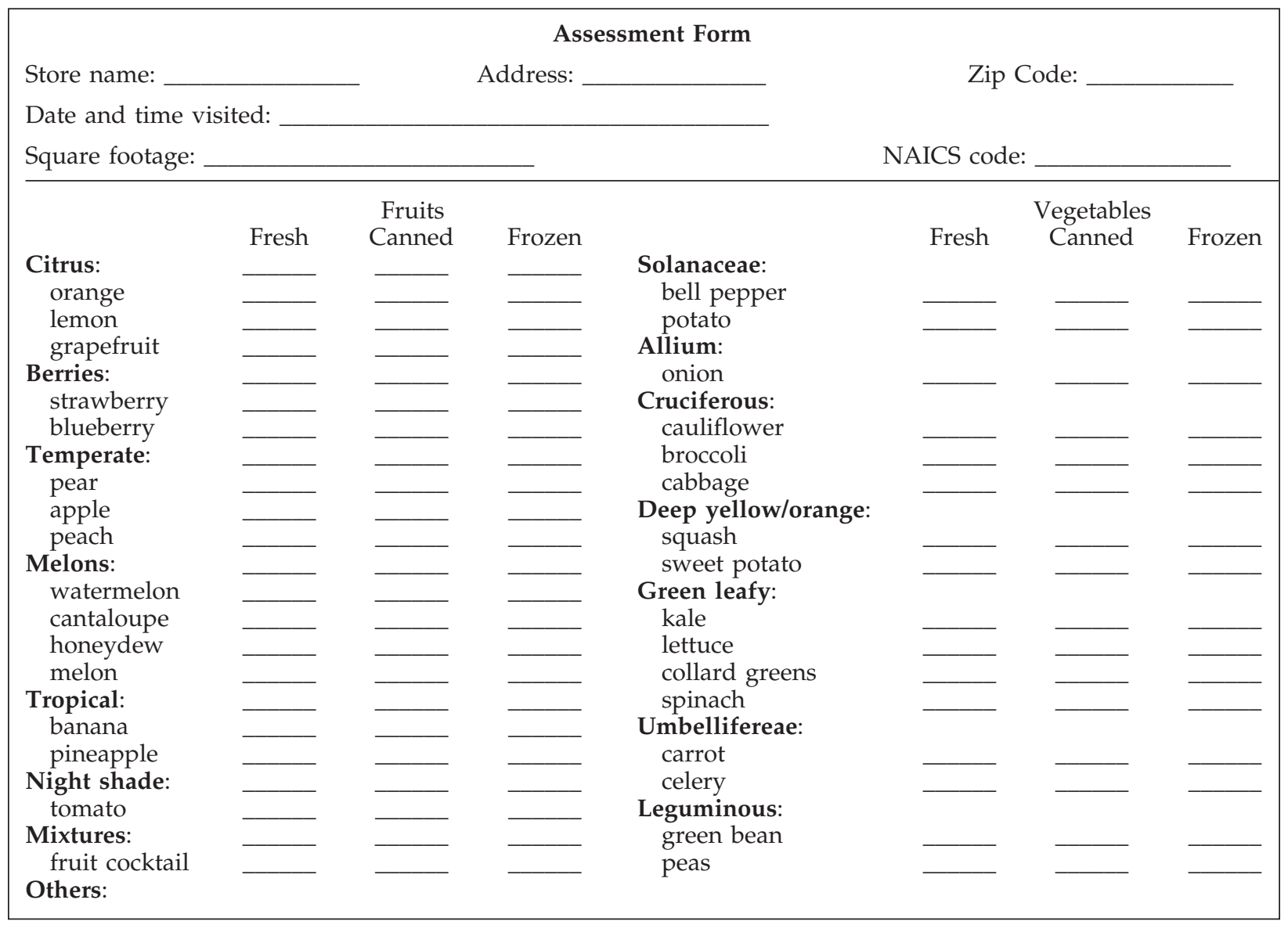

FIG. 1. Assessment form

\section{Data collection}

The non-participant observer approach was employed to investigate each food store's selection of fruits and vegetables. Briefly, we physically went into each store and documented what they had available without purchasing anything. Of the 51 original food stores, three stores were padlocked during posted business hours, even after second and third attempts. Two stores were added during the course of the study because they were erected in the time period between the study's design and implementation, two stores that were originally identified were closed down or moved at the time of store visits, and one store manager refused to be included in the study, bringing the total number of stores visited to $47 .^{8}$

\section{Statistical analysis}

Data from this study fell into both categorical and continuous categories in that food stores were classified according to four categories and the number of fruit and vegetable types was measured on a continuous numeric scale. Descriptive statistics were used to describe, organize, and summarize data on each community and their respective local food environments (see Table 1). To further describe the local food environments of each community, measures of central tendency were computed at both the community and food store level. Fruit and veg- etable means were calculated as the total number of items in each fruit/vegetable category divided by the number of stores. Means were calculated for each type of store and done as an aggregate according to community. Between communities comparisons were performed using independent samples t-tests to investigate differences in availability of fruits and vegetables based on the zip code where the store was located (see Table 2). Inferential statistics were used to draw conclusions about differences in the availability of fruits and vegetables (whether fresh, canned, or frozen) between communities. Analysis of variance (ANOVA) was used to evaluate both the main effects of zip code and store type and the interaction of zip code and store type with regard to availability of fruits and vegetables (see Table 3). The SAS General Linear Model procedure (PROC GLM) was used to perform a two-way ANOVA model to study the effects of the two factors (region and store type) separately and together via interaction term on the means of the fruit and vegetable types. Significance of findings was determined at a level of $\mathrm{p} \leq 0.05 .^{9}$

\footnotetext{
${ }^{8}$ Bailey, DM. Research for the Health Professional: A Practical Guide. 2nd ed: F.A. Davis Company, 1997.

${ }^{9}$ Bailey, DM. Research for the Health Professional: A Practical Guide.
} 
Table 1. Housing and Demographic Characteristics of Studied Communities

\begin{tabular}{|c|c|c|}
\hline Characteristics & $\begin{array}{c}\text { Community } A \\
(14226)\end{array}$ & $\begin{array}{c}\text { Community } B \\
(14215)\end{array}$ \\
\hline Total population & 29,382 & 44,484 \\
\hline \multicolumn{3}{|l|}{ Racial/ethnic minority concentration } \\
\hline$\%$ White alone & 88 & 22.7 \\
\hline$\%$ Black or African American alone & 5.9 & 72.3 \\
\hline \multicolumn{3}{|l|}{ Age } \\
\hline Median age in years & 39.6 & 31.6 \\
\hline \multicolumn{3}{|l|}{ Sex } \\
\hline$\%$ Female & 53.7 & 54.8 \\
\hline \multicolumn{3}{|l|}{ Educational attainment } \\
\hline$\%$ No schooling & 0.32 & 0.78 \\
\hline$\%$ Less than high school & 7.8 & 19.4 \\
\hline \% High school diploma & 20 & 30.7 \\
\hline$\%$ Some college & 18.2 & 24.5 \\
\hline$\%$ College degree & 31.4 & 18.8 \\
\hline$\%$ Graduate and beyond degree & 22.4 & 5.8 \\
\hline \multicolumn{3}{|l|}{ Employment in civilian labor force } \\
\hline \% Únemployed & 4.4 & 9.9 \\
\hline$\%$ Employed & 95.6 & 90.1 \\
\hline \multicolumn{3}{|l|}{ Household income } \\
\hline Median income in dollars & $\$ 46,380$ & $\$ 27,338$ \\
\hline \multicolumn{3}{|l|}{ Poverty } \\
\hline \% Household income below poverty level & 7.8 & 22.6 \\
\hline$\%$ Household income at or above poverty level & 92.2 & 77.4 \\
\hline$\%$ Receive public assistance & 2 & 9.2 \\
\hline \multicolumn{3}{|l|}{ Housing value } \\
\hline Median value of housing units in dollars & $\$ 93,600$ & $\$ 52,500$ \\
\hline \multicolumn{3}{|l|}{ Tenure } \\
\hline$\%$ Owner-occupied housing units & 73.3 & 54.0 \\
\hline$\%$ Renter-occupied housing units & 26.7 & 46.0 \\
\hline \multicolumn{3}{|l|}{ Occupancy } \\
\hline$\%$ Vacant housing units & 3.7 & 11.8 \\
\hline \multicolumn{3}{|l|}{ Vehicles available to household } \\
\hline \% 0 Vehicles & 8.1 & 23.8 \\
\hline$\% 1$ Vehicle & 41.0 & 47.1 \\
\hline$\% 2$ or more Vehicles & 50.9 & 29.2 \\
\hline
\end{tabular}

Source: U.S. Bureau of the Census, Census 2000.

\section{RESULTS}

Community A, which is the area with zip code 14226 , is a suburban community with a total population of 29,382 people. According to year 2000 US Census data, 88 percent of its residents are White and five percent are Black. Community B, which is separated from Community A by just a street, is the area with zip code 14215. Community B has a total population of 44,484 people. Black residents make up 72.3 percent of its population and 22.7 percent are White. Table 1 summarizes the neighborhood characteristics of each community. The median household income in Community A is nearly double what it is in Community B ( $\$ 46,380$ vs. $\$ 27,338)$. The median value for owner-occupied housing units in Community B is $\$ 52,500$, and nearly twelve percent of the housing units in this area are vacant. The median value for owner-occupied housing units in Community A is \$93,600, and only four percent of the housing units in this community are considered vacant. Table 1 shows that both communities have similar distributions of family and non-fam- ily households, but the majority of housing units in Community A are owner-occupied (73.3 percent), while there is a $50 / 50$ mix of renters and owners in Community B. ${ }^{10}$

Table 2 outlines the mean number of fruit and vegetable types available in each community. Mean values represent the average number of food items available in the specific category (fresh fruits, frozen vegetables, etc) across all store types in the corresponding community. Food stores in the predominantly African American community generally offered fewer varieties of fruit and vegetables than food stores in the predominantly White community. This finding was statistically significant in the categories of fruits and vegetables overall $(\mathrm{p}=0.02)$, all fruits $(\mathrm{p}=0.01)$, fresh fruits $(p=0.02)$, canned fruits $(p=0.02)$, all vegetables $(\mathrm{p}=0.05)$, and fresh vegetables $(\mathrm{p}=0.01)$.

Trends of higher fruit and vegetable availability in Community A were driven by the types of food stores in each community. Community A had a total of 11 food

\footnotetext{
${ }^{10}$ US Bureau of the Census. "Profile of General Demographic Characteristics for Zctas 14215 and 14226."
} 
Table 2. T-test Comparing Availability of Fresh, Canned, and Frozen Fruits and Vegetables in a Predominantly Black Community (Community B) with a Predominantly White Community (Community A)

\begin{tabular}{|c|c|c|c|c|c|}
\hline \multirow[b]{2}{*}{ Fruit and vegetable types } & \multicolumn{2}{|c|}{$\begin{array}{c}\text { Community A } \\
\text { Zip code } 14226 \\
\text { Population 29,382 } \\
\text { Stores } 11\end{array}$} & \multicolumn{2}{|c|}{$\begin{array}{c}\text { Community B } \\
\text { Zip code } 14215 \\
\text { Population } 44,484 \\
\text { Stores } 36\end{array}$} & \multirow[b]{2}{*}{ Sig. } \\
\hline & Mean & $S D$ & Mean & $S D$ & \\
\hline Fruits and vegetables & 30.55 & 19.21 & 14.5 & 9.7 & 0.021 \\
\hline Fruits & 13.73 & 7.27 & 6.53 & 3.8 & 0.009 \\
\hline Fresh fruits & 5.64 & 4.95 & 1.31 & 1.89 & 0.016 \\
\hline Canned fruits & 7.09 & 2.39 & 5.08 & 2.01 & 0.023 \\
\hline Frozen fruits & 1 & 1.41 & 0.14 & 0.54 & 0.074 \\
\hline Vegetables & 16.82 & 12.76 & 7.97 & 6.21 & 0.047 \\
\hline Fresh vegetables & 8.18 & 6.49 & 1.92 & 2.58 & 0.01 \\
\hline Canned vegetables & 5 & 2.9 & 4.39 & 1.74 & 0.519 \\
\hline Frozen vegetables & 3.64 & 4.37 & 1.67 & 2.75 & 0.182 \\
\hline
\end{tabular}

$\mathrm{SD}$, standard deviation; Sig., significance/p-value.

Equal variances not assumed

stores; three supermarkets, two grocery stores, two corner or convenience stores, and four stores classified as "other." Community B had a total of 36 food stores, which included one supermarket, seven grocery stores, 26 corner or convenience stores, and two stores classified as "other." Table 3 outlines the differences among the four types of food store included in analysis (e.g., supermarkets, grocery stores, corner or convenience stores, and other), according to fruit and vegetable category and zip code. Fruit and vegetable means according to store type were significantly different from each other in all categories except fresh and canned fruits in Community A. Multiple comparison t-tests showed that supermarkets were the store type significantly different from other store types in all instances ( $p$ values ranging from $<0.01$ to 0.04 ). Supermarkets, which offered the largest varieties of fruit and vegetable types, were more abundant in Community A than in Community B.

Additionally, store types offering the most types of fruits and vegetables (e.g., supermarkets and grocery stores) offered less fruit and vegetable types in Community B as compared to Community A. For example, grocery stores in Community A on average offered seven varieties of fresh fruit while grocery stores in Community $B$ on average offered two varieties of fresh fruit. Table 3 shows that the effect of zip code on store was statistically significant in the categories of fresh fruits and vegetables $(p=0.03)$ and canned vegetables $(p=0.04)$ in grocery stores. Identical store types in both zip codes were not significantly different from each other in the categories of canned fruits, frozen fruits, total fruits, frozen vegetables, total vegetables, and total fruits and vegetables.

\section{DISCUSSION}

In summary, food stores in a predominantly African American community (Community B) offered fewer varieties of fresh fruit and vegetables compared with food stores in a bordering predominantly White community (Community A). Additionally, food stores with fewer va- rieties of fruit and vegetables were more prevalent in Community B compared with Community A. This difference was observed among the four levels of store type (e.g., supermarkets, grocery stores, corner or convenience stores, and other). Community B had a lower prevalence of the stores that offered the largest fruit and vegetable varieties than Community $\mathrm{A}$.

Our findings of only one supermarket in Community B with a population of 44,484 residents compared with three such stores in Community A with a population of 29,382 residents is consistent with existing literature that suggest that poor and predominantly Black communities have less access to healthy food sources and a variety of healthy food options. Moreover, the results also suggest the importance of including characteristics of the local food environment into future studies to gain a better understanding of barriers to healthy eating. ${ }^{11}$

This study offered a low-cost method for assessing a community's nutritional environment. The assessment tool created is a fairly crude estimate of the availability of fruits and vegetables in food stores and may introduce observer bias. However, this simple assessment method clearly provides an image of disparity. Additionally, physical canvassing of communities is a strength of the study as it ensured that even unofficial businesses, which may not be listed in the phone book, have the chance to be included. At the same time, stores could have been

${ }^{11}$ Morland, K, S Wing, A Diez-Roux, and C Poole. "Neighborhood Characteristics Associated with the Location of Food Stores and Food Service Places.": 23-29; Yen, IH and GA Kaplan. "Neighborhood Social Environment and Risk of Death: Multilevel Evidence from the Alameda County Study.": 898-907; Sloane, DC, AL Diamant, LB Lewis, AK Yancey, G Flynn, LM Nascimento, WJ McCarthy, JJ Guinyard, MR Cousineau, and REACH Coalition of the African American Building a Legacy of Health Project. "Improving the Nutritional Resource Environment for Healthy Living through Community-Based Participatory Research." Journal of General Internal Medicine 18 (2003): 568-75; Macdonald, L, S Cummins, and S Macintyre. "Neighbourhood Fast Food Environment and Area Deprivation-Substitution or Concentration?" Appetite 49, no. 1 (2007): 251-54. 
Table 3. Multiple Comparisons t-Test Comparing Availability of Fresh, Canned, and

Frozen Fruits and Vegetables in Each Store Type in a Predominantly Black Community (Community B) with a Predominantly White Community (Community A)

\begin{tabular}{|c|c|c|c|c|c|c|}
\hline \multirow[b]{3}{*}{ Fruit and vegetable types } & \multicolumn{4}{|c|}{$\begin{array}{c}\text { Community A } \\
\text { Zip code 14226, population 29,382 }\end{array}$} & \multirow{3}{*}{\multicolumn{2}{|c|}{ Sig Diff }} \\
\hline & \multirow{2}{*}{$\begin{array}{c}\begin{array}{c}\text { Supermkt } \\
(n=3)\end{array} \\
\text { Mean }(S D)\end{array}$} & \multirow{2}{*}{$\begin{array}{c}\begin{array}{c}\text { Grocery } \\
(n=2)\end{array} \\
\text { Mean }(S D)\end{array}$} & \multirow{2}{*}{$\begin{array}{c}\begin{array}{c}\text { Corner/ } \\
\text { convenient } \\
(n=2)\end{array} \\
\text { Mean }(S D)\end{array}$} & \multirow{2}{*}{$\begin{array}{c}\begin{array}{c}\text { Other } \\
(n=4)\end{array} \\
\text { Mean }(S D)\end{array}$} & & \\
\hline & & & & & & \\
\hline Fruits and vegetables & $58(4)$ & $30(1)$ & $11(4)$ & $21(8)$ & $37(<0.01)$ & Supmkt \\
\hline Fruits & $23(7)$ & $12(3)$ & $7(1)$ & $11(3)$ & $8(0.01)$ & Supmkt \\
\hline Fresh fruits & $12(4)$ & $7(1)^{*}$ & $0(0)$ & $4(2)$ & $9(<0.01)$ & Supmkt \\
\hline Canned fruits & $9(1)$ & $5(5)$ & $7(1)$ & $7(1)$ & $2(0.15)$ & $\mathrm{NA}$ \\
\hline Frozen fruits & $2(2)$ & $1(1)$ & $0(0)$ & $1(1)$ & $2(0.26)$ & NA \\
\hline Vegetables & $35(3)$ & $18(4)$ & $4(2)$ & $10(5)$ & $30(<0.01)$ & Supmkt \\
\hline Fresh vegetables & $16(1)$ & $12(3)^{*}$ & $0(0)$ & $5(3)$ & $20(<0.01)$ & Supmkt Grocery \\
\hline Canned vegetables & $9(2)$ & $4(2)^{*}$ & $4(2)$ & $4(1)$ & $9(0.01)$ & Supmkt \\
\hline \multirow[t]{2}{*}{ Frozen vegetables } & $10(2)$ & $2(3)$ & $0(0)$ & $2(1)$ & $21(<0.01)$ & Supmkt \\
\hline & \multirow[b]{2}{*}{$\begin{array}{c}\text { Supermkt } \\
(n=1)\end{array}$} & \multicolumn{3}{|c|}{$\begin{array}{c}\text { Community B } \\
\text { Zip code 14215, population 29,382 }\end{array}$} & & \\
\hline \multirow[b]{2}{*}{ Fruit and vegetable types } & & $\begin{array}{l}\text { Grocery } \\
(n=7)\end{array}$ & $\begin{array}{l}\text { Corner/ } \\
\text { convenient } \\
(n=25)\end{array}$ & $\begin{array}{l}\text { Other } \\
(n=2)\end{array}$ & & \\
\hline & Mean (SD) & Mean (SD) & Mean (SD) & Mean (SD) & $F(\mathrm{p}$-value $)$ & Sig Diff \\
\hline Fruits and vegetables & 50 (NA) & $21(5)$ & $11(6)$ & $25(2)$ & $21(<0.01)$ & Supmkt \\
\hline Fruits & 19 (NA) & $8(2)$ & $5(3)$ & $12(1)$ & $13(<0.01)$ & Supmkt \\
\hline Fresh fruits & 8 (NA) & $2(1)^{*}$ & $1(1)$ & $5(1)$ & $18(<0.01)$ & Supmkt Other \\
\hline Canned fruits & 8 (NA) & $6(1)$ & $5(2)$ & $7(0)$ & $3(0.04)$ & NA \\
\hline Frozen fruits & 3 (NA) & $0.3(0.5)$ & $0(0)$ & $0(0)$ & $66(<0.01)$ & Supmkt \\
\hline Vegetables & 31 (NA) & $13(4)$ & $5(4)$ & $13(3)$ & $23(<0.01)$ & Supmkt \\
\hline Fresh vegetables & 13 (NA) & $3(1)^{*}$ & $1(1)$ & $6(1)$ & $32(<0.01)$ & Supmkt Other \\
\hline Canned vegetables & 8 (NA) & $6(1)^{*}$ & $4(1)$ & $4(0)$ & $7(<0.01)$ & Supmkt \\
\hline Frozen vegetables & 10 (NA) & $4(3)$ & $1(2)$ & $4(2)$ & $13(<0.01)$ & Supmkt \\
\hline
\end{tabular}

SD, standard deviation; $\mathrm{n}$, number of food stores; NA, not applicable.

Sig Diff, store types significantly different in multiple comparison t-test.

*Identical store types significantly different according to zip code.

missed by just using the phone book and a physical inspection to search for them. Physical inspection of stores could have also introduced the possibility of observer bias. The time spent assessing stores could have varied based on the level of personal comfort on the part of the investigator, which could mean that each store wasn't assessed with the same level of scrutiny. To reduce the level of bias, the investigator was encouraged to request assistance from store management if necessary or return to the store at another time if attention to detail was compromised in any way.

Future studies are needed that include a wider geographic area and examine store inventory lists and turnover of products. It may also be useful to include other potential indicators of availability and access to fruits and vegetables, such as average distances from homes to food stores, availability of vehicle to household, modes of transportation, accessibility to public transportation, neighborhood crime rates adjacent to food stores, price, and quality of available fruits and vegetables. It is recog- nized that we can't be certain that people living in a given neighborhood actually do their food shopping there, and without a determination of where residents actually shop we can not rule out the possibility that residents of Community B do their food shopping in Community A. However, the importance of this study's findings that a disparity did exist with respect to the availability of healthy foods in bordering communities of differing racial/ethnic composition reinforced previous studies that have documented relationships between food availability and health status at the aggregate and individual level. ${ }^{12}$

${ }^{12}$ Morland, K, S Wing, and A Diez-Roux. "The Contextual Effect of the Local Food Environment on Residents' Diets: The Atherosclerosis Risk in Communities Study.": 1761-67; Morland, K, AV Diez-Roux, and S Wing. "Supermarkets, Other Food Stores, and Obesity: The Atherosclerosis Risk in Communities Study.": 333-39; Wrigley, N, D Warm, and B Margetts. "Deprivation, Diet, and Food Retail Access: Findings from the Leeds 'Food Deserts' Study." Environment \& Planning A 35, no. 1 (2003): 151-88. 


\section{CONCLUSIONS}

Our results indicate that fruits and vegetables were available to both communities. However, the minority community had fewer varieties, especially fresh fruits and fresh vegetables, available to them and thus fewer options for incorporating these into their diets. We also found a lower proportion of supermarkets in the minority community. It is unfortunate that since 1992, when Congress reported on the "Urban Grocery Gap," this problem still exists, which shows that we have not come very far in solving this problem. The free market is not working to get healthy foods into the neediest communities. Grocers understand that the money to be made is in the wealthier communities; therefore, they limit choice and selection in areas where they know they won't make as much money. While observational and anecdotal data support this apparent disparity, it is important that such environmental inequalities be objectively studied and reported in the literature. Policy makers and healthcare professionals can use this data to generate the next steps in developing a research agenda that will address and eliminate this disturbing phenomenon.

\section{ACKNOWLEDGMENT}

This work was supported by the following grants: DAMD17-02-1-0252, 1 P20 CA96256-01A1， 1 R03 CA103475-01 and R01 ES11368.

\section{BIBLIOGRAPHY}

Appel, LJ, WM Vollmer, E Obarzanek, KM Aicher, PR Conlin, BM Kennedy, JB Charleston, PM Reams, and DASH Collaborative Research Group. "Recruitment and Baseline Characteristics of Participants in the Dietary Approaches to Stop Hypertension Trial." Lournal of the American Dietetic Association 99 (1999): S69-S75.

Bailey, DM. Research for the Health Professional: A Practical Guide. 2nd ed: F.A. Davis Company, 1997.

Baker, E, C Kelly, E Barnidge, J Strayhorn, M Schootman, J Struthers, and D Griffith. "The Garden of Eden: Acknowledging the Impact of Race and Class in Efforts to Decrease Obesity Rates." American Journal of Public Health 96 (2006): 1170-74.

Cheadle, A, BM Psaty, S Curry, E Wagner, P Diehr, T Koepsell, and A Kristal. "Community-Level Comparisons between the Grocery Store Environment and Individual Dietary Practices." Preventive Medicine 20 (1991): 250-61.

Conlin, PR, D Chow, ER Miller, LP Svetkey, P-H Lin, DW Harsha, TJ Moore, FM Sacks, LJ Appel, and DASH Research Group. "The Effect of Dietary Patterns on Blood Pressure Control in Hypertensive Patients: Results from the Dietary Approaches to Stop Hypertension (Dash) Trial." American Journal of Hypertension 13 (2000): 949-55.

Dagenais, GR, R Marchioli, S Yusuf, and G Tognoni. "BetaCarotene, Vitamin C, and Vitamin E and Cardiovascular Diseases." Current Cardiology Reports 2 (2000): 293-99.

Deckelbaum, RJ, EA Fisher, M Winston, S Kumanyika, RM Lauer, FX Pi-Sunyer, S St. Jeor, EJ Schaefer, and IB Weinstein. "Summary of a Scientific Conference on Preventive
Nutrition: Pediatrics to Geriatrics." Circulation 100 (1999): 450-56.

Eisenhauer, E. "In Poor Health: Supermarket Redlining and Urban Nutrition." GeoJournal 53 (2001): 125-33.

Gaziano, JM, JE Manson, LG Branch, GA Colditz, WC Willett, and JE Buring. "A Prospective Study of Consumption of Carotenoids in Fruits and Vegetables and Decreased Cardiovascular Mortality in the Elderly." Annals of Epidemiology 5 (1995): 255-60.

Glanz, K, M Basil, E Maibach, J Goldberg, and D Snyder. "Why Americans Eat What They Do: Taste, Nutrition, Cost, Convenience, and Weight Control Concerns as Influences on Food Consumption." Lournal of the American Dietetic Association 98 (1998): 1118-26.

Houston, DK, J Stevens, J Cai, and PS Haines. "Dairy, Fruit, and Vegetable Intakes and Functional Limitations and Disability in a Biracial Cohort: The Atherosclerosis Risk in Communities Study." American Journal of Clinical Nutrition 81 (2005): 515-22.

Jetter, KM and DL Cassady. "The Availability and Cost of Healthier Food Alternatives." American Journal of Preventive Medicine 30, no. 1 (2006): 38-44.

Joshipura, KJ, FB Hu, JE Manson, MJ Stampfer, EB Rimm, FE Speizer, G Colditz, A Ascherio, B Rosner, D Spegelman, and WC Willett. "The Effect of Fruit and Vegetable Intake on Risk for Coronary Heart Disease." Annals of Internal Medicine 134 (2001): 1106-14.

Karanja, NM, E Obarzanek, P-H Lin, ML McCullough, KM Phillips, JF Swain, CM Champagne, KP Hoben, and DASH Collaborative Research Group. "Descriptive Characteristics of the Dietary Patterns Used in the Dietary Approaches to Stop Hypertension Trial." Journal of the American Dietetic Association 99 (1999): S19-S27.

Kaufman, PR, JM MacDonald, SM Lutz, and DM Smallwood. "Do the Poor Pay More for Food? Item Selection and Price Differences Affect Low-Income Household Food Costs." Washington, DC: United States Department of Agriculture, Economic Research Service, 1997.

Macdonald, L, S Cummins, and S Macintyre. "Neighbourhood Fast Food Environment and Area Deprivation-Substitution or Concentration?" Appetite 49, no. 1 (2007): 251-54.

Morland, K, AV Diez-Roux, and S Wing. "Supermarkets, Other Food Stores, and Obesity: The Atherosclerosis Risk in Communities Study." American Journal of Preventive Medicine 30, no. 4 (2006): 333-39.

Morland, K, S Wing and A Diez-Roux. "The Contextual Effect of the Local Food Environment on Residents' Diets: The Atherosclerosis Risk in Communities Study." American Journal of Public Health 92 (2002): 1761-67.

Morland, K, S Wing, A Diez-Roux, and C Poole. "Neighborhood Characteristics Associated with the Location of Food Stores and Food Service Places." American Journal of Preventive Medicine 22 (2002): 23-29.

Morrill, AC and CD Chinn. "The Obesity Epidemic in the United States." Iournal of Public Health Policy 25, no. 3-4 (2004): 353-66.

Obarzanek, E, FM Sacks, WM Vollmer, GA Bray, ER Miller, P-H Lin, NM Karanja, MM Most-Windhauser, TJ Moore, JF Swain, CW Bales, MA Proschan, and DASH Research Group. "Effects on Blood Lipids of a Blood Pressure-Lowering Diet: The Dietary Approaches to Stop Hypertension (Dash) Trial." American Journal of Clinical Nutrition 74 (2001): 80-89. 
Sloane, DC, AL Diamant, LB Lewis, AK Yancey, G Flynn, LM Nascimento, WJ McCarthy, JJ Guinyard, MR Cousineau, and REACH Coalition of the African American Building a Legacy of Health Project. "Improving the Nutritional Resource Environment for Healthy Living through Community-Based Participatory Research." Iournal of General Internal Medicine 18 (2003): 568-75.

Solomons, NW. "Diet and Long-Term Health: An African Diaspora Perspective." Asia Pacific Journal of Clinical Nutrition 12 (2003): 313-30.

Suter, P. "The Effects of Potassium, Magnesium, Calcium, and Fiber on Risk of Stroke." Nutrition Reviews 57 (1999): $84-88$.

Tucker, K. "Dietary Patterns and Blood Pressure in African Americans." Nutrition Reviews 57 (1999): 356-58.

Turrell, G. "Structural, Material, and Economic Influences of the Food Purchasing Choices of Socioeconomic Groups." Australia New Zealand Journal of Public Health 20 (1996): 11-17.

UB Center for Urban Studies School of Architecture and Planning, UB Center for Research in Primary Care, and The Black Leadership Forum. "The Health Status of the near East Side Black Community: Wellness and Neighborhood Conditions." Buffalo, NY, 2001.

US Bureau of the Census. "1997 Naics Definitions." 2000.

. "Profile of General Demographic Characteristics for Zctas 14215 and 14226." US Bureau of the Census, 2000.

US House of Representatives Select Committee on Hunger. "Obtaining Food: Shopping Constraints of the Poor, Committee Report." Washington, DC: US Government Printing Office, 1987.

. "Urban Grocery Gap, Committee Report." Washington, DC: US Government Printing Office, 1992.
Vogt, TM, LJ Appel, E Obarzanek, TJ Moore, WM Vollmer, LP Svetkey, FM Sacks, GA Bray, JA Cutler, MM Windhauser, P-H Lin, NM Karanja, and DASH Collaborative Research Group. "Dietary Approaches to Stop Hypertension: Rationale, Design, and Methods." Journal of the American Dietetic Association 99 (1999): S12-S18.

Wechsler, H, CE Basch, P Zybert, R Lantigua, and S Shea. "The Availability of Low-Fat Milk in an Inner-City Latino Community: Implications for Nutrition Education." American Journal of Public Health 85 (1995): 1690-92.

Wrigley, N, D Warm, and B Margetts. "Deprivation, Diet, and Food Retail Access: Findings from the Leeds 'Food Deserts' Study." Environment \& Planning A 35, no. 1 (2003): $151-88$.

Yen, IH and GA Kaplan. "Neighborhood Social Environment and Risk of Death: Multilevel Evidence from the Alameda County Study." American Journal of Epidemiology 149 (1999): 898-907.

Zenk, S, A Schultz, B Israel, J Sherman, S Bao, and M Wilson. "Neighborhood Racial Composition, Neighborhood Poverty, and the Spatial Accessibility of Supermarkets in Metropolitan Detroit." American Journal of Public Health 95 (2005): 660-67.

Address correspondence to: Edith M. Williams Institute for Partnerships to Eliminate Health Disparities University of South Carolina 220 Stoneridge Drive, Suite 208 Columbia, SC 29210

E-mail: willi425@gwm.sc.edu 
This article has been cited by:

1. Diana S. Grigsby-Toussaint, Shannon N. Zenk, Angela Odoms-Young, Laurie Ruggiero, Imelda Moise. 2010. Availability of Commonly Consumed and Culturally Specific Fruits and Vegetables in African-American and Latino Neighborhoods. Journal of the American Dietetic Association 110:5, 746-752. [CrossRef] 